\title{
Ingress/Egress Incidents Involving Wheelchair Users in a Fixed-Route Public Transit Environment
}

\author{
Karen L. Frost, Gina Bertocci, Sheryll Sison \\ University of Louisville
}

\begin{abstract}
The objectives of this study were to characterize the ingress and egress activities of wheeled mobility device (WhMD) passengers using fixed-route large, accessible transit vehicles (LATVs), and to examine factors associated with incidents occurring on ramps. A retrospective review of public transit video surveillance footage of WhMDseated passengers accessing fixed-route LATVs was conducted. Ingress and egress activities were characterized based on travel conditions and characteristics of the WhMD and LATV ramp. Incidents were identified based on predetermined criteria, and chi-square analysis was performed to identify WhMD and/or ingress/egress characteristics associated with incidents. Video records of 250 WhMD trips were analyzed. A total of 39 incidents occurred during ingress and 12 incidents occurred during egress. Results indicated that the frequency of incidents was significantly greater for scooter users and passengers who ascended the ramp using a rear-facing WhMD orientation. Narrow LATV ramp width was associated with the greatest number of incidents, followed by problems related to LATV door width and steep ramp slope.
\end{abstract}

\section{Introduction}

Fixed-route, large, accessible transit vehicles (LATVs) provide the opportunity for wheeled mobility device (WhMDs) users to independently participate in everyday 
activities, including traveling to and from employment, shopping, healthcare, and social and recreational activities. However, 20 years after the passage of the Americans With Disabilities Act (ADA), WhMD users still encounter obstacles to safe and accessible use of fixed-route LATVs (Buning et al. 2007; Fitzgerald et al. 2007).

In general, LATVs represent a relatively safe mode of travel (Shaw and Gillispie 2003). This is due in large part to overall vehicle mass and the slow speed of LATV travel associated with intercity routes. Despite this relatively safe environment, the U.S. National Highway Transportation Safety Administration (NHTSA) reported that 35 percent of injuries and deaths that occurred between 1990-1995 involving wheelchair users were due to improper or no securement of the wheelchair, with 17 percent of these incidents occurring in LATVs. Additionally, 25 percent of overall injuries or deaths involving wheelchair users were attributed to either lift malfunctions or falling on/off a ramp during ingress/egress (National Highway Traffic Safety Administration 1997).

The authors previously conducted a retrospective records review of six years of WhMD-related adverse incident reports maintained by a metropolitan transit agency (Frost and Bertocci 2010). Findings revealed that the majority of adverse incidents occurred when the LATV was stopped during ingress/egress (42.6\%). Furthermore, injuries were more likely to result from incident scenarios involving a combination of the WhMD tipping and the passenger falling from the WhMD (61.8\%). These incident scenarios were 1.8 times more likely to happen during ingress/egress than while at the securement station (either during transit or when LATV was stopped).

Ingress and egress involve many factors that may contribute directly or indirectly to an adverse incident. These factors include the WhMD, the WhMD-seated passenger's navigational skills, the built environment (e.g., surface terrain, sidewalk height, lamp posts), and adaptive transportation equipment (vehicle ramp). This study sought to provide an in-depth review of video surveillance footage of WhMD ingress and egress activities on LATVs in order to characterize aspects of the ingress and egress process, and to provide a more comprehensive understanding of factors associated with adverse incidents during ingress and egress. Characteristics of the ingress/egress environment, WhMDs, and ingress/egress scenarios are described and quantified, and adverse incidents are summarized and examined to identify factors associated with unsuccessful outcomes. 


\section{Research Methods}

Approval to conduct this study was obtained from the University of Louisville Institutional Review Board (IRB No. 170.07)

\section{Video Recordings}

Digital video surveillance footage of WhMD activities on LATVs was obtained from a metropolitan transit agency located in the southeastern region of the U.S. during the 21-month period of June 2007 through February 2009. Signs were posted in each camera-equipped LATV notifying passengers that activities within the bus were being monitored and recorded for public safety.

During the period of the study, the transit agency operated 57 LATVs that were equipped with the GE ${ }^{\circledast}$ MobileView III Video Surveillance System ${ }^{\circledast}$ (GE Security, Bradenton, FL). This system records digital video images at a rate of $30 \mathrm{frames} / \mathrm{sec}-$ ond with up to $640 \times 480$ pixel resolution. Each video surveillance system consists of 4-5 permanently-mounted video cameras. One camera is directed at the front door to capture all WhMD ingress and egress events. This camera view includes the front door, access ramp, and approximately one-meter distance beyond the LATV door (Figure 1).

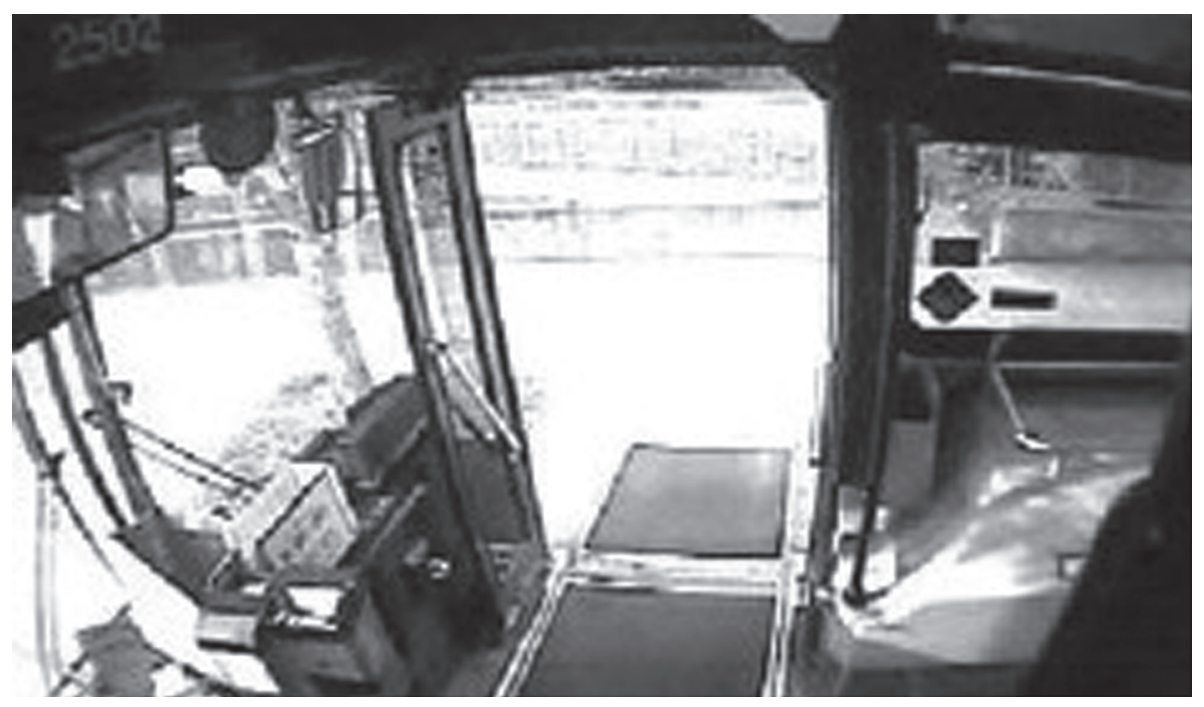

Figure 1. Output from GE ${ }^{\circledR}$ Security's WaveReader Software 
Video footage was logged onto a $120 \mathrm{~GB}$ digital video recorder (DVR) that recorded a continuous loop for 30 hours. DVRs are interchangeable storage disks that can be removed from the LATV and inserted into a docking station that allows viewing and recording of video and audio footage on a connected computer using $G^{\oplus}$ WaveReader software. Randomly-selected DVRs were reviewed by the researchers 2-3 times per month throughout the two-year study period. All ingress and egress events involving WhMD-seated passengers were recorded and analyzed using $\mathrm{GE}^{\ominus}$ WaveReader viewing software.

\section{Data Collection and Analysis}

Ingress and egress events were recorded per trip or per WhMD-seated passenger. Thus, a video record contained one ingress and one egress event. Ingress and egress events were abstracted and recorded as categorical and continuous data using a FileMaker Pro 8 database (Ver. 2 for Mac OS X). Ingress was defined as starting when the front wheels of the WhMD contacted the LATV ramp, and ending when the rear wheels of the WhMD contacted the vehicle floor and were off the ramp. Egress was defined as starting when the front wheels of the WhMD contacted the LATV ramp and ending when the rear wheels of the WhMD left the ramp and contacted outside surface terrain.

All ingress and egress events were characterized based on three categories of data: general travel data, WhMD data, and ingress/egress data. These variables are defined in Table 1. Additionally, the LATV ramp (Lift U® Division, Hogan Manufacturing; Escalon, $C A$ ) is mechanically interlocked with the kneeling suspension of the vehicle, preventing ramp deployment without vehicle kneeling. Thus, each ramp deployment indicates that the LATV was kneeled, although the extent of kneeling could not be determined based on video review.

A difficulty was defined as either an ingress or egress event involving two or more maneuvering attempts by the WhMD-seated passenger or a minor impact with an interior or exterior LATV component(s) while the WhMD was in contact with the ramp. A minor impact was defined as an impact that did not cause the WhMD to come to a stop. An incident was defined as an event during which the WhMD tipped and/or the passenger fell from the WhMD, or the WhMD and/or passenger had a major impact with an interior or exterior LATV component while the WhMD was in contact with ramp. A major impact was defined as an impact that caused the WhMD to stop moving in its predetermined direction. 
Descriptive statistics were used to present summary information describing general travel data and WhMD and ingress/egress characteristics. Independent samples chi-square analysis was performed to examine difficulties and incidents based on WhMD type, weather condition, whether or not bags/items were carried by the passenger or attached to the WhMD, ramp extension level, surface terrain, and WhMD orientation on the ramp. All statistical analysis was conducted using PASW (formerly SPSS) statistical software (Ver. 17 for Mac OS X).

\section{Table 1. Variable Definitions}

\begin{tabular}{|c|c|}
\hline Variable & Definition \\
\hline WhMD Type & Manual wheelchair, power wheelchair, scooter. \\
\hline Time of Travel & $\begin{array}{l}\text { Daytime (between 6:00am - 6:00pm) or Evening/Night ( }>6: 00 \mathrm{pm} \\
\text { and < 6:00am). }\end{array}$ \\
\hline Weather Condition & Sun, overcast, rain, snow, cannot determine. \\
\hline Ingress Time of Process & $\begin{array}{l}\text { Period of time beginning when front wheels of WhMD contacted } \\
\text { ramp and ending when rear wheels contacted vehicle floor and } \\
\text { were off ramp. }\end{array}$ \\
\hline Egress Time of Process & $\begin{array}{l}\text { Period of time beginning when front wheels of wheelchair } \\
\text { contacted ramp and ending when rear wheels contacted outside } \\
\text { terrain and were off ramp. }\end{array}$ \\
\hline Ramp Extension Level & Street, sidewalk \\
\hline Surface Terrain & $\begin{array}{l}\text { Smooth concrete/pavement, uneven concrete/ pavement, dirt/ } \\
\text { grass, gravel. }\end{array}$ \\
\hline WhMD Orientation & Forward-facing or rear-facing. \\
\hline Assistance Required & Whether or not passenger used assistance to board/exit LATV. \\
\hline $\begin{array}{l}\text { Assistance Provided by } \\
\text { Whom }\end{array}$ & LATV operator, personal assistant, other passenger. \\
\hline Difficulty & $\begin{array}{l}\text { Events involving } 2 \text { or more maneuvering attempts by passenger } \\
\text { and/or a minor impact (bump) with LATV component(s) that did } \\
\text { not cause WhMD to come to a stop. }\end{array}$ \\
\hline Incident & $\begin{array}{l}\text { Events during which WhMD tipped and/or passenger fell from } \\
\text { WhMD, WhMD and/or passenger impacted LATV door/frame or } \\
\text { other object while WhMD was in contact with ramp and such im- } \\
\text { pact caused the WhMD to come to a stop, or a WhMD wheelchair } \\
\text { component broke/dropped. }\end{array}$ \\
\hline
\end{tabular}




\section{Results}

The participating metropolitan transit agency serves a population of approximately 1.3 million and operates 240 large, accessible, public transit vehicles. The transit agency estimates approximately $250 \mathrm{WhMD}$ boardings per week, averaging 10,400-13,000 annual WhMD trips. During the 21-month period (June 2007 - February 2009), video recordings of $250 \mathrm{WhMD}$ trips were reviewed and abstracted (each WhMD trip consisted of one ingress event and one egress event). Because DVRs record data over a 30-hour continuous loop, there were instances in which a DVR contained a video record of an ingress event but not the corresponding egress event, or partial video of an ingress or egress event. This was the case for nine WhMD trips. In one instance, partial video of the ingress process was missing, and in eight cases, some or all video of the egress process was missing. As a result, sample size variations exist among the data and figures presented.

The geographic region sits on a wide, flat flood plane with gently rolling hills. The mean annual temperature is $56.9^{\circ} \mathrm{F}\left(13^{\circ} \mathrm{C}\right)$; with annual temperatures ranging from an average low of $47.9^{\circ} \mathrm{F}\left(8.3^{\circ} \mathrm{C}\right)$ to an average high of $66.0^{\circ} \mathrm{F}\left(18.9^{\circ} \mathrm{C}\right)$ (NOAA 2009). The average monthly precipitation is 3.7 inches $(9.4 \mathrm{~cm}$ ) (NOAA 2009). Consistent with the moderate climate, weather conditions during the majority of WhMD trips were fair/dry ( $n=237 ; 94.8 \%)$. Rain/wet weather was only observed during 13 WhMD trips ( $n=13 ; 5.2 \%)$. The greatest percentages of trips were observed during summer and fall $(n=104 ; 41.6 \%$ and $n=74 ; 29.6 \%$, respectively), followed by trips during winter and spring ( $n=53 ; 21.2 \%$ and $n=19 ; 7.6 \%$, respectively).

The number of male passengers observed traveling was approximately 10 percent greater $(n=138 ; 55.2 \%)$ than females $(n=112 ; 44.8 \%)$. However, more female passengers $(n=25 ; 61.0 \%)$ were observed traveling during evening/overnight hours (6:00 pm to $6: 00 \mathrm{am}$ ) compared to their male counterparts ( $n=16 ; 41.6 \%)$.

\section{WhMD Data}

The majority of observed WhMD trips were taken by passengers who used a power wheelchair $(n=168 ; 67.2 \%)$. Passengers who used a manual wheelchair $(n=64 ; 25.6 \%)$ were observed less frequently, followed by scooter users $(n=18$; 7.2\%) (Figure 2). Nine passengers used and/or were equipped with an additional form of assistive technology during travel; three WhMD passengers carried a cane, three traveled with service dogs, two had augmentative communication devices mounted to the WhMD, and another passenger had a tray mounted to his WhMD. 


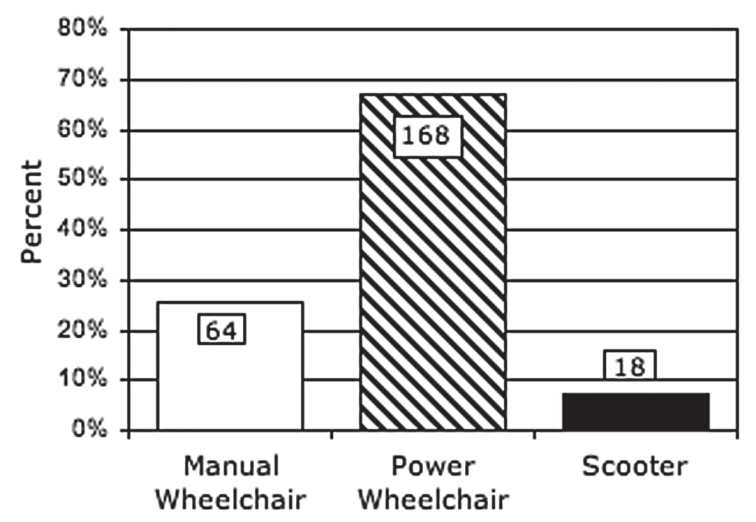

\section{Figure 2. Distribution of WhMDs Observed During All Ingress/Egress Events $(n=250)$}

Seventy-five percent of all passengers either had a backpack/bag attached to their WhMD or carried a package/item by hand or other means. In the majority of cases ( $n=111 ; 76.0 \%)$, a backpack/bag was attached to the WhMD. Fewer passengers carried a package/item $(n=97 ; 38.8 \%)$ using their hand or arm or by placing the package/item in their lap or on their footrest.

\section{Ingress Data}

Ingress Events-Ramp Extension Level, Surface Terrain, WhMD Orientation and Assistance Provided. Frequency and percentage data for all ingress events are provided in Table 2. During ingress, the ramp was most often extended to sidewalk level ( $n=228 ; 91.2 \%$ ). Ingress from street level occurred far less frequently $(n=20 ; 8.0 \%)$. In two cases passengers ambulated into the LATV using the ramp; one passenger carried a manual wheelchair into the LATV, and another passenger ambulated while using his/her manual wheelchair as a walker. The outside surface terrain was typically smooth concrete/pavement $(n=204 ; 81.6 \%)$. A smaller but equal number of passengers had to traverse uneven concrete/pavement $(n=22$; $8.8 \%)$ or dirt/grass $(n=22 ; 8.8 \%)$ prior to contact with the ramp. In two cases $(0.8 \%)$, the surface terrain could not be reliably determined. 
Table 2. Percentage and Frequency Data for Ingress and Egress Variables

\begin{tabular}{|c|c|c|}
\hline & Ingress $(n=250)$ & Egress $(n=244)$ \\
\hline \multicolumn{3}{|l|}{ Ramp Extension Level } \\
\hline Sidewalk & $91.2 \%(228)$ & $79.1 \% \quad(193)$ \\
\hline Street & $8.0 \% \quad(20)$ & $18.9 \% \quad(46)$ \\
\hline Could not be determined & - & $1.2 \%(3)$ \\
\hline Other/not applicable & $0.1 \% \quad(2)$ & $0.8 \%(2)$ \\
\hline \multicolumn{3}{|l|}{ Surface Terrain } \\
\hline Smooth concrete/pavement & $81.6 \%(204)$ & $78.8 \%(197)$ \\
\hline Uneven concrete/pavement & $8.8 \% \quad(22)$ & $12.3 \% \quad(30)$ \\
\hline Dirt/grass & $8.8 \% \quad(22)$ & $5.7 \% \quad(14)$ \\
\hline Could not be determined & $0.8 \% \quad(2)$ & $1.2 \%$ \\
\hline \multicolumn{3}{|l|}{ WhMD Orientation on Ramp } \\
\hline Forward-facing & $72.0 \%$ & $99.2 \%(242)$ \\
\hline Rear-facing & $27.2 \%(68)$ & $0.0 \% \quad(0)$ \\
\hline Not applicable (ambulated) & $0.8 \% \quad(2)$ & $0.4 \%$ \\
\hline \multicolumn{3}{|l|}{ Assistance Provided by Whom } \\
\hline No assistance & $87.2 \%(218)$ & $81.9 \%$ (199) \\
\hline Bus operator & $7.2 \% \quad(18)$ & $14.0 \% \quad(34)$ \\
\hline $\begin{array}{l}\text { Personal assistant/Traveling } \\
\text { companion }\end{array}$ & $2.9 \% \quad$ (7) & $2.9 \%(7)$ \\
\hline Other passenger & $1.2 \% \quad(3)$ & $1.2 \%(3)$ \\
\hline
\end{tabular}

The majority of passengers $(n=180 ; 72.0 \%)$ ascended the ramp using a forwardfacing WhMD orientation (Figure 3 ). These passengers were predominantly power wheelchair users $(n=135 ; 75.0 \%)$, followed by manual wheelchair users $(n=35$; $19.4 \%)$ and scooter users $(n=10 ; 5.6 \%)$. Passengers who ascended the ramp using a rear-facing WhMD orientation $(n=68 ; 27.2 \%)$ also were more likely to be power wheelchair users $(n=33 ; 48.5 \%)$, followed closely by manual wheelchair users $(n=27 ; 39.7 \%)$, then scooter users $(n=8 ; 11.8 \%)$. Most passengers boarded the bus without assistance $(n=217 ; 87.1 \%)$. When assistance was provided during ingress, it was most often provided by the LATV operator $(n=18 ; 7.2 \%)$ or a personal assistant/traveling companion ( $n=10 ; 4.0 \%)$. In a few cases, assistance was provided by another passenger $(n=3 ; 1.2 \%)$. 


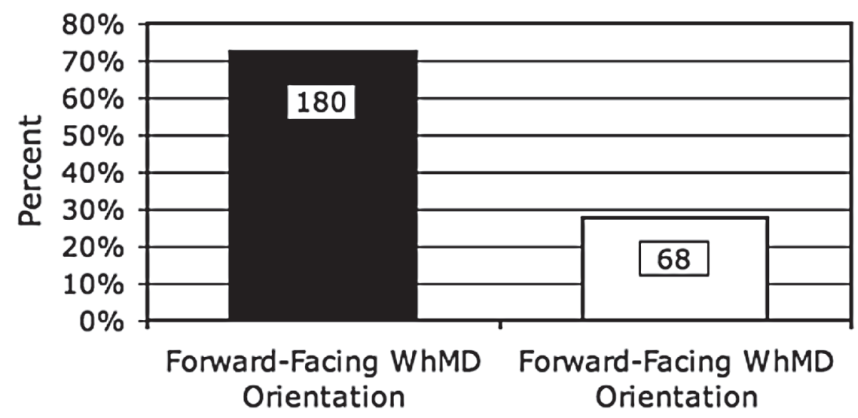

Figure 3. WhMD Orientation on Ramp During Ingress $(n=248)$

\section{Ingress Events-Overview of Incidents and Difficulties, Time to Complete} Ingress. Video recordings were examined to determine whether or not a difficulty or incident (as defined in Table 1) occurred during ingress. Of the $250 \mathrm{WhMD}$ trips reviewed, one ingress event ( $0.4 \%)$ involved an incident and 38 ingress events (15.3\%) were classified as involving difficulty, totaling 39 (15.6\%) ingress incidents/ difficulties. The single incident occurred during early afternoon, in light rain, and involved a male passenger who used a 3-wheeled scooter. The LATV was at a designated bus stop and the ramp was extended to a smooth concrete sidewalk. The scooter user approached the ramp using a forward-facing orientation and ascended the ramp to the point that the forward-most wheel crossed the interior vehicle threshold at the top of the ramp. Forward motion of the WhMD then stopped, and the passenger appeared to shift his body position slightly forward while toggling the controller with his right hand. The scooter and passenger then began to descend the ramp rearward. As the rear wheels contacted the exterior rubber threshold at the base of the ramp, the front wheel of the scooter began to rise upward off of the ramp surface. The scooter rotated rearward and toward the front of the vehicle, then fell to the sidewalk on its right side. The passenger fell rearward, landing on his buttocks and posterior torso (Figure 4). The passenger did not appear to be wearing a postural support lap belt. The passenger stated he was not injured and declined the LATV operator's request to call an emergency medical service. 


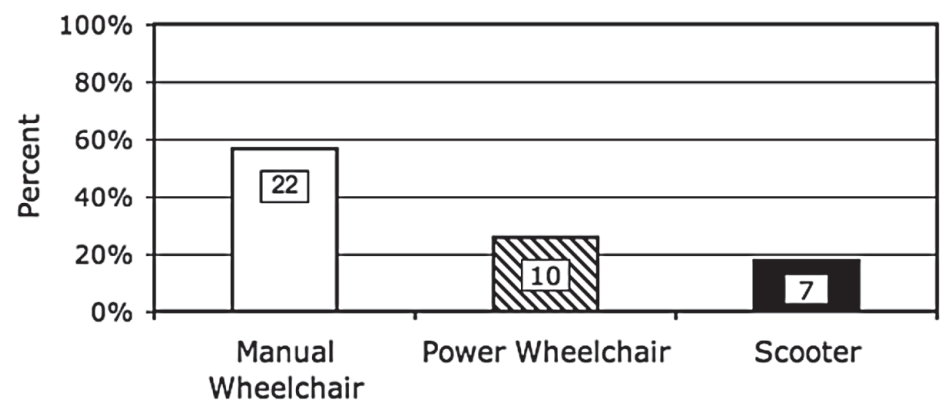

\section{Figure 4. Distribution of WhMDs Involved in Incidents/Difficulties During Ingress $(n=39)$}

Video review of the 38 ingress events categorized as difficult revealed many instances of WhMD passengers encountering apparent difficulty due to the narrow width of the ramp. Seventeen videos revealed WhMDs contacting ramp edge barriers such that the impact required them to descend the ramp, in full or in part, and re-align their WhMD before ascending successfully. In 6 of these 17 videos, the WhMD required three or more attempts before successfully boarding the LATV. Nine videos showed WhMD passengers encountering difficulty related to the narrow width of the LATV door, as evidenced by impacting the LATV door. In two videos, WhMD passengers impacted both the LATV door and ramp edge barrier(s). Each instance required the passenger to descend the ramp and re-align the WhMD before ascending and entering the LATV successfully. Seven videos revealed apparent difficulties related to the slope of the ramp. These videos displayed a similar scenario: as the WhMD approached the top of the ramp, forward motion slowed or stopped, giving the appearance that the WhMD did not have enough power to overcome either the ramp slope or interior vehicle threshold; the passenger descended rearward down the ramp before attempting to ascend again. Two manual wheelchairs users and one power wheelchair user ascended almost to the top of the ramp, then reached out and grabbed a door handrail to pull themselves up the remainder of the ramp and into the LATV. In another instance, the LATV operator re-kneeled the bus and re-deployed the ramp before a scooter user was able to successfully ascend the ramp. Three videos indicated WhMD passengers had difficulties crossing the exterior ramp threshold, and in three videos the surface terrain adjacent to the ramp appeared to be the primary cause of WhMD passenger difficulties. In the first difficulty related to surface terrain, the left edge of the ramp was resting on the curb cut and the right edge of the ramp was resting on the sidewalk, creating a cross slope. In the other two difficulties, the ramp was 
extended to a parcel of grass between the street and sidewalk, and the apparent uneven terrain required the WhMD passenger to make multiple maneuvers prior to successfully crossing the exterior ramp threshold. In one of these situations, another passenger assisted the WhMD passenger by pushing the WhMD.

Mean time to complete ingress for events that did not involve an incident or difficulty was 5.28 seconds ( \pm 7.43 seconds). For the subset of 38 ingress events that involved difficulty, mean time to complete ingress was 19.58 seconds ( \pm 16.54 ). Only one ingress event involved an incident, and the time to complete ingress during this event was 2 minutes, 31 seconds.

\section{Ingress Incidents \& Difficulties-Descriptive Statistics and Chi Square Analy-}

sis. Because only one event was categorized as an incident, it was combined with the 38 events categorized as difficulties, resulting in 39 ingress incidents/difficulties that were analyzed in further detail. Incidents/difficulties occurred in 15.6 percent of total ingress events.

The majority of ingress incidents/difficulties occurred during daytime hours ( $n=34$; $87.2 \%)$. Passengers who experienced an incident/difficulty were predominantly power wheelchair users $(n=22 ; 56.4 \%)$, followed by manual wheelchair $(n=10$; $25.6 \%$ ) and scooter ( $n=7 ; 17.9 \%)$ users (Figure 5$)$. Although scooter users represented a small percentage (7.2\%) of all WhMD passengers, more than a third of scooter users (38.89\%) experienced an incident/difficulty during ingress. Similarly, a smaller percentage of WhMD passengers ascended the ramp using a rear-facing orientation $(30.8 \% /)$, yet more than two thirds of these passengers experienced an incident/difficulty ( $n=27 ; 69.2 \%$ ). Over half of the WhMD passengers who experienced an incident/difficulty carried a bag or item ( $n=22 ; 56.4 \%)$, and many had a backpack or bag attached to the WhMD $(n=16 ; 41.0 \%)$. During most ingress incidents/difficulties, the ramp was extended to sidewalk level ( $n=36 ; 92.3 \%)$, and the surface terrain leading to the ramp was smooth concrete or pavement $(n=31$; 79.5\%). Weather did not appear to be a factor associated with incidents/difficulties. Weather conditions were fair/dry in all but two incidents/difficulties $(n=37$; 94.9\%). Rain was present during one difficulty and during the single incident. 

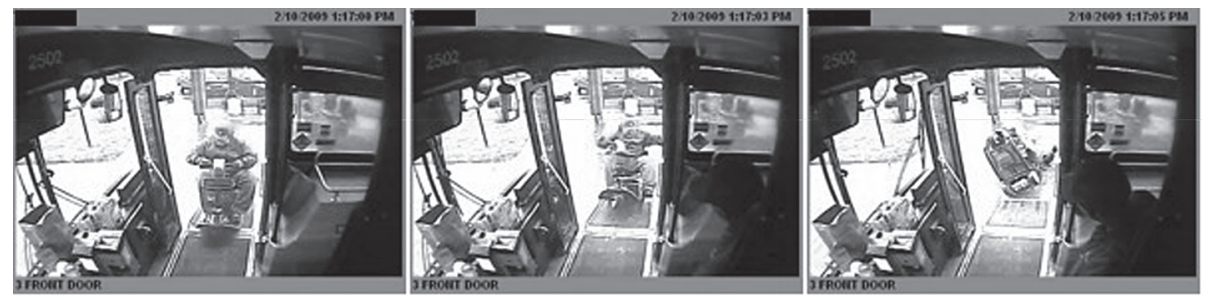

Figure 5. Video Footage of Ingress Incident

Analysis to compare successful ingress events to those that resulted in an incident or difficulty showed mixed results. Chi-square analysis confirmed the observation that the number of incidents/difficulties involving scooter users was significantly greater than expected $\left(\chi^{2}(1)=8.1, p=0.017\right)$. Analysis also revealed that significantly more incidents/difficulties occurred when passengers used a rear-facing WhMD orientation during ingress $\left(\chi^{2}(1)=40.36, p<0.001\right)$ rather than forwardfacing WhMD orientation. Fewer incidents/difficulties than were expected occurred when a backpack or bag was attached to the WhMD, and this result also was significant $\left(\chi^{2}(1)=5.161, p=0.023\right)$. There was no significant difference between successful ingress events and incidents/difficulties during ingress based on ramp extension level, surface terrain, weather condition, or whether or not bags/items were carried by the passenger.

\section{Egress Data}

As mentioned previously, the continuous loop video recording system yielded partial video records for some WhMD trips. During three WhMD trips, partial video of the egress process was recorded, and there was no video depicting egress activity for six WhMD trips. As a result, sample size variations exist among the data and figures presented. Frequency and percentage data for all egress events is provided in Table 2.

Egress Events-Ramp Extension Level, Surface Terrain, WhMD Orientation, and Assistance Provided. During egress, the ramp was extended to the sidewalk level $(n=193 ; 79.1 \%)$ more often than street level ( $n=46 ; 18.9 \%)$. In three events ramp extension level could not be determined, and in two events ( $0.8 \%)$ it was categorized as "other." In one of these events, the ramp was deployed to a grasscovered slope. In the other event, the LATV was not aligned parallel to the sidewalk curb cut; the right edge of the deployed ramp rested on the street, and the left edge rested on the curb cut several inches above street level. 
Surface terrain beyond the ramp was typically smooth concrete/pavement ( $n=197 ; 80.7 \%)$, followed by uneven concrete/pavement $(n=30 ; 12.3 \%)$ then dirt/ grass $(n=14 ; 5.7 \%)$. In three cases (1.2\%), the surface terrain could not be determined with certainty. Similar to ingress, most passengers exited the LATV without assistance ( $n=199 ; 81.9 \%)$. When assistance was provided during egress, it was most often provided by the LATV operator $(n=34 ; 14.0 \%)$. In several cases, assistance was provided by a personal assistant/traveling companion $(n=7 ; 2.9 \%)$ and in a few cases by another passenger $(n=3 ; 1.2 \%)$.

Egress Events-Overview of Incidents and Difficulties, Time to Complete Ingress. One incident and 11 difficulties were observed during egress. The single incident during egress occurred during early afternoon on a fair/dry day, and involved a female passenger who used a power wheelchair. Two canvas bags were looped around and behind the wheelchair headrest, and a purse was looped around the left armrest. The LATV stopped parallel to the designated bus stop and the ramp was deployed onto a smooth concrete sidewalk. The passenger's WhMD appeared to be properly aligned within the ramp edge barriers as the passenger approached the top of the ramp. However, as the front wheels crossed the interior vehicle threshold, the right front wheel began turning toward the right ramp edge barrier, and the rear casters began moving toward the left LATV doorframe. The passenger's forward motion continued, and the front right wheel drove over the ramp edge barrier. The WhMD pitched forward causing one rear caster to rise off the ramp surface (Figure 6). A passerby and the LATV operator provided immediate assistance. The passerby lifted the front of the WhMD and placed the front wheels back onto the ramp surface while the operator tilted the WhMD rearward. The LATV operator provided the passenger with verbal guidance to re-align her WhMD and assisted her down the ramp by holding the WhMD seatback canes until the passenger successfully exited the ramp. The WhMD-seated passenger was uninjured and remained seated in her WhMD throughout the incident.
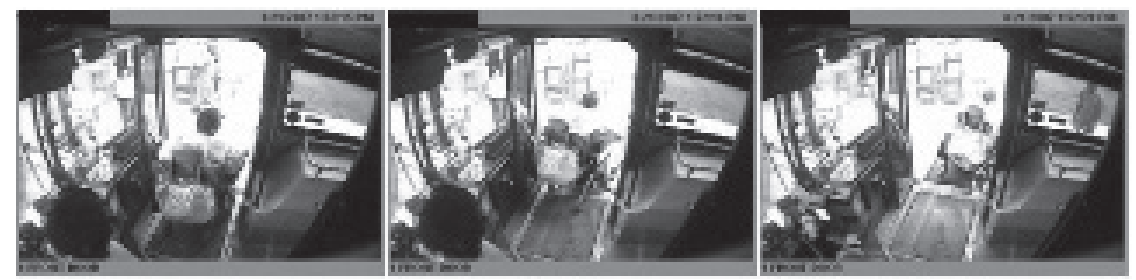

Figure 6. Video Footage of Egress Incident 
The majority of difficulties encountered by WhMD passengers during egress appeared to be related to issues involving a combination of ramp slope and narrow ramp width. Six videos revealed WhMD passengers impacting the ramp edge barriers; requiring them to reverse direction and/or re-align their wheels in order to descend the ramp successfully. Three events involved the front wheel of a power wheelchair becoming wedged in the gap between the LATV door and the ramp edge barrier (Figure 7). In four videos, the passenger turned the WhMD at the base of the ramp before the rear wheels cleared the ramp; in one of these videos, the LATV operator assisting the WhMD passenger turned the WhMD too early. In each of these four situations, the WhMD tilted laterally as a rear wheel drove over the ramp edge barrier. Only one of these difficulties appeared related to the surface terrain beyond the ramp.

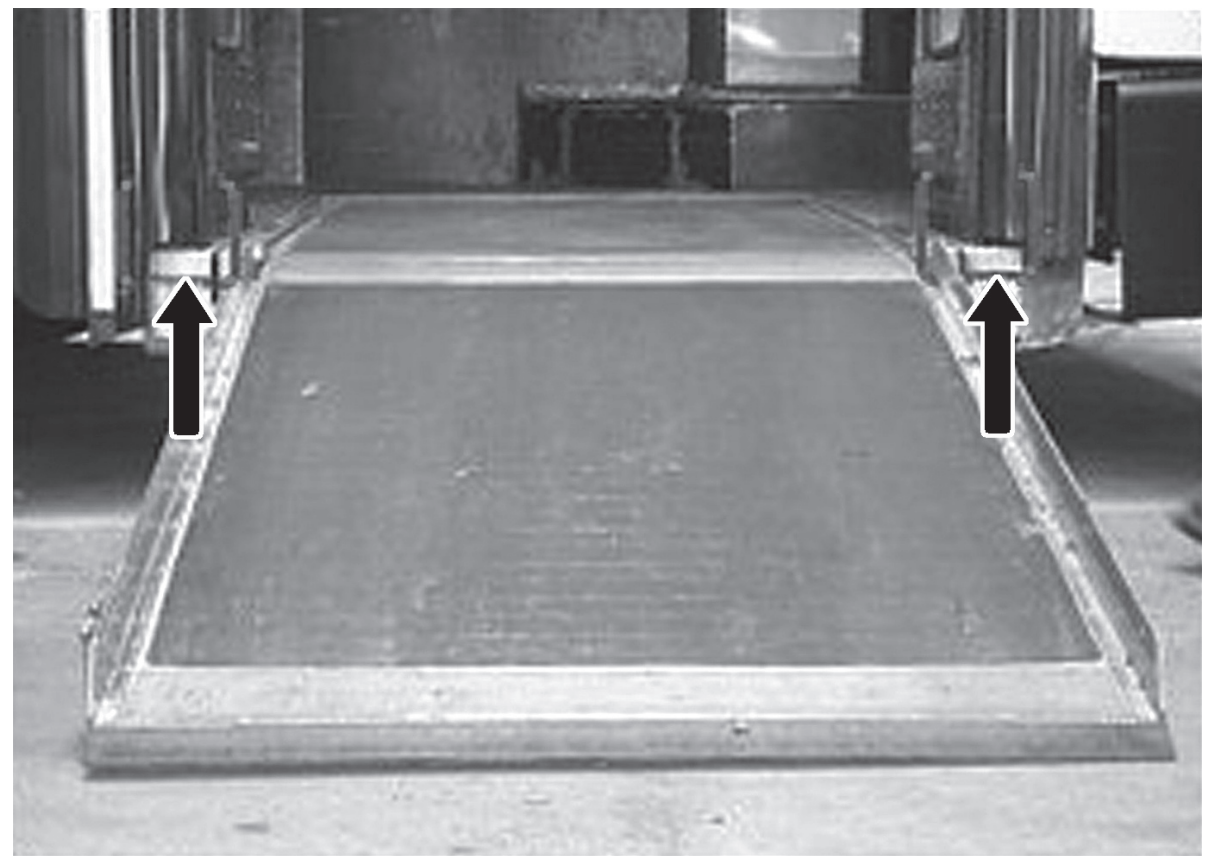

\section{Figure 7. Horizontal Gap between LATV Door and Ramp Edge Barrier}

Mean time to complete the egress process for events that did not involve an incident or difficulty was 4.21 seconds ( \pm 3.12 ). For the subset of 11 difficult events, mean egress time was 8.36 seconds $( \pm 6.53$ ). The time required to complete egress for the one incident was 33 seconds. 
Egress Incidents \& Difficulties-Descriptive Statistics and Chi Square Analysis. For purposes of this analysis, the single egress incident was combined with egress events categorized as difficulties, resulting in 12 ingress incidents/difficulties that were analyzed in further detail. Incidents/difficulties occurred in 4.9 percent of the egress events.

The majority of egress incidents/difficulties occurred during daytime hours ( $n=11$; 91.7\%). Passengers who experienced an incident/difficulty were predominantly power wheelchair users $(n=10 ; 83.3 \%)$; only one manual wheelchair $(8.3 \%)$ and one scooter user (8.3\%) were involved in an incident/difficulty (Figure 8). When normalized by WhMD type, power wheelchair users were found to have the greatest incidence (5.9\%) of difficulty during egress. Fifty-percent $(n=6)$ of WhMD users carried a bag or item, and most had a backpack or bag attached to their WhMD $(n=8 ; 66.7 \%)$. Weather conditions were fair/dry in all but two incidents/difficulties $(n=10 ; 83.3 \%)$, and rain was present during one egress event.

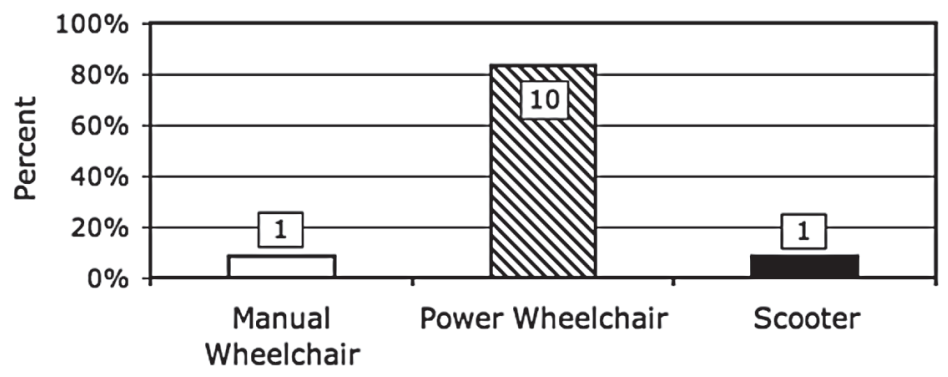

\section{Figure 8. Distribution of WhMDs Involved in Incidents/Difficulties during Egress $(n=12)$}

During most egress incidents/difficulties the ramp was extended to sidewalk level $(n=8 ; 66.7 \%)$, and the surface terrain beyond the ramp was smooth concrete or pavement $(n=7 ; 58.3 \%)$. Uneven concrete or pavement was present during three incidents/difficulties (25.0\%), dirt or grass was observed in one instance (8.3\%), and the surface terrain could not be reliably determined in one instance (8.3\%). Chi-square analysis indicated no significant difference between successful egress events and those that resulted in an incident/difficulty based on WhMD type, weather condition, ramp extension level, surface terrain or whether or not bags/ items were carried by the passenger or attached to the WhMD. 


\section{Discussion}

To our knowledge, this is the first observational study of WhMD activities on LATVs based on in-vehicle video footage of actual events. Our objective was to characterize ingress and egress events to provide a better understanding of difficulties and incidents experienced by WhMD-seated passengers in the LATV environment.

Our findings indicate that LATV ingress and egress present a barrier to independent WhMD transport. WhMD users frequently have difficulty when attempting to board or exit an LATV. Difficulties and incidents were three times more likely to occur during ingress than egress. They were also more likely to occur during ingress when the WhMD passenger ascended the ramp using a rear-facing WhMD orientation, or if the passenger used a scooter. This particular transit agency recommends that WhMD-seated passengers ascend the ramp in a rear-facing orientation during ingress. A rear-facing orientation helps maintain the combined center of gravity of the WhMD and passenger toward the uphill portion of the ramp and closer to the LATV, increasing stability and reducing the risk of tipping. However, traversing rearward up a relatively narrow, sloped surface requires significant navigational skill, and is not a viable option for some WhMD users. Our observations suggest that visibility issues related to neck range of motion and/or limited visibility of the front casters associated with being overweight or obese may contribute to difficulties when aligning the WhMD at the base of the ramp and/or maintaining proper alignment while ascending/descending.

Narrow ramp width appeared to be associated with the greatest number of difficulties/incidents during both ingress and egress. During ingress, 17 difficulties were associated with an inability to maintain $\mathrm{WhMD}$ alignment within the ramp; and during egress, 6 difficulties were associated with issues related to narrow ramp width. The majority of difficulties involved the wheels of the WhMD impacting the ramp edge barrier(s); requiring the passenger to partially or completely descend/ ascend the ramp to re-align their WhMD before proceeding with ingress or egress. During ingress difficulties, most WhMD passengers were able to successfully ascend the ramp on their second try, but in six instances, WhMD passengers required three or more tries before successfully entering the LATV. Additionally, physical and/or verbal assistance by the LATV operator was necessary in six egress cases and seven ingress cases. The transit agency's LATVs are equipped with foldout Lift-U $\mathrm{U}^{\odot}$ ramps manufactured by Hogan Manufacturing, Inc. (Escalon, CA). The ramp platform surface width (between edge barriers) on model 2008 and 2009 
LATVs was measured by the researchers at $76.2 \mathrm{~cm}$ (30 in). Although compliant with $A D A$ requirements, this ramp width allows for less than $2 \mathrm{~cm}$ of maneuvering space on either side of a "common wheelchair" $(76.2 \mathrm{~cm}$ width $x 121.9 \mathrm{~cm}$ length, or 30 in width $\times 48$ in length) as defined by the ADA. Bariatric or "over-sized" wheelchairs, which are becoming more common (LaPlante 2003), may exceed the specified "common wheelchair" dimensions, resulting in even less maneuvering clearance when attempting to use the ramp. We observed three passengers using bariatric wheelchairs in this study. Regardless of WhMD overall dimensions, video observations of actual ingress and egress activities indicate that navigation up or down an inclined ramp, with little clearance on either side of the WhMD, can be very challenging. These observations indicate a need for additional study regarding the effect of ramp width on successful ingress and egress given variations in WhMD passenger navigational skills and WhMD dimensions. We also recommend that ramp and LATV manufacturers further explore the need and potential design implications of wider access ramps.

The narrow LATV front entry door width was also associated with difficulties. Video observations showed nine instances in which the WhMD either struck one or both of the folding entry doors or a WhMD armrest was retained in a handrail mounted to the door during ingress. In these cases, passengers had to partially descend the ramp and re-align the WhMD before successfully navigating through the LATV door. No difficulties were observed related to door width during egress; however, the authors have previously reported instances where the WhMD struck the door during egress (Frost and Bertocci 2010). These findings suggest that LATV vehicle manufacturers would be warranted in examining the cost-benefit of designing a wider front entry door or collapsing handrails. During egress, the presence of a gap between the ramp edge barriers and LATV door was also associated with challenges. This gap, measuring $5.08 \mathrm{~cm}(2 \mathrm{in})$ on each side, enables the ramp to fold into the floor of the LATV. It was found that slight misalignment of the WhMD with the ramp during egress contributed to wheels becoming lodged in this gap, preventing WhMD passengers from descending the ramp. Attention to such design details at the interface between the ramp and vehicle is critical to enhancing accessibility and safety for WhMD passengers traveling in LATVs. Difficulties related to LATV door and ramp width emphasize the need for LATV vehicle and ramp manufacturers to work together to identify solutions to improve WhMD passenger safety. 
Ramp slope appeared to be associated with 7 of 39 difficulties/incidents during ingress and a contributing factor in 7 of 12 difficulties/incidents during egress. Interestingly, in each of these cases the ramp was deployed to the sidewalk, not street level. We had expected to observe more difficulties related to ramp slope when the ramp was extended to street level. Only one difficulty involving ramp slope occurred when the ramp was extended to street level. In this case, a female passenger using a scooter was not able to successfully ascend the ramp after two attempts, requiring the LATV operator re-kneel the LATV and redeploy the ramp prior to successful ingress. The ADA Accessibility Specifications for Transportation Vehicles (U.S. Architectural and Transportation Barriers Compliance Board [Access Board] 1990) state that ramps shall have the least slope practicable. However, as currently written, it is virtually impossible to assure compliance with these ramp slope requirements (Table 3), given variations in the environment (e.g., curb height), road surface terrain, and the extent of vehicle kneeling implemented by the LATV operator.

Table 3. ADA Ramp Slope Specifications for Buses and Vans*

\begin{tabular}{|l|l|}
\hline Ramp Deployment Level & Maximum Slope \\
\hline Ground [street] level & $1: 4$ \\
\hline Vehicle floor $<3$ in above 6-inch curb & $1: 4$ \\
\hline Vehicle floor $>3$ in and $<6$ in above 6-inch curb & $1: 6$ \\
\hline Vehicle floor $>6$ in and $<9$ in above 6-inch curb & $1: 8$ \\
\hline Vehicle floor $>9$ in above 6-inch curb & $1: 12$ \\
\hline
\end{tabular}

*ADA Accessibility Specifications for Transportation Vehicles, Subpart B-Buses, Vans and Systems

Since no known data have been published describing actual LATV ramp slopes in the built environment, we measured ramp angles on the same LATVs used in this study during full kneeling and minimal kneeling conditions when the ramp was extended both to street and sidewalk level. Ramp angles measured with the ramp deployed to the street ranged from 1:4 (fully kneeled) to 1:3.2 (minimally kneeled). Ramp angles measured with the ramp deployed to the sidewalk curb ranged from 1:8.1 (fully kneeled) to 1:5.7. Given the measured heights from the vehicle floor to the ground, these findings indicate non-compliance with ADA ramp slope requirements for minimally kneeled conditions (Table 4). These findings further highlight the need for educating LATV operators on the impact that vehicle kneeling can have on ramp slope, and subsequently, WhMD passenger access and safety. This 
exercise also illustrates that the current ADA ramp slope specifications, as written, are impractical to apply in the highly variable built environment.

Table 4. Actual LATV Ramp Angles

\begin{tabular}{|l|c|c|}
\hline $\begin{array}{l}\text { LATV Height Based on Kneel Condition } \\
\text { (measured from ground surface to LATV floor) }\end{array}$ & $\begin{array}{c}\text { Sidewalk Level } \\
\mathbf{( 1 5 . 2 4} \mathbf{~ c m ~ / ~ 6 ~ i n ~} \\
\text { curb) (degrees) }\end{array}$ & $\begin{array}{c}\text { Street } \\
\text { Level } \\
\text { (degrees) }\end{array}$ \\
\hline Fully Kneeled (27.94 cm/11.0 in) & 7 & 14 \\
\hline Minimally Kneeled $(35.56 \mathrm{~cm} / 14.0 \mathrm{in})$ & $10^{*}$ & $17^{*}$ \\
\hline
\end{tabular}

${ }^{*}$ Angles exceed ADA maximum ramp slope specifications (49 CFR Part 38). When height of vehicle floor is $>15.24 \mathrm{~cm}$ ( $6 \mathrm{in}$ ) and $\leq 22.86 \mathrm{~cm}$ (9 in) above a $15.24 \mathrm{~cm}$ (6 in) curb, a maximum slope of 1:8 (7 degrees) is permitted; when ramp is deployed to ground level, slope shall not exceed a maximum slope of 1:4 (14 degrees).

In late 2008, the U.S. Architectural and Transportation Barriers Compliance Board (Access Board) published its second draft of proposed revisions to the ADA Accessibility Guidelines for Buses and Vans for public comment. The proposed revision regarding ramp slopes reads: "Ramps and bridgeplates shall have slopes not steeper than 1:6 (9.5 degrees) when deployed to boarding and alighting areas without station platforms and to the roadway" (www.access-board.gov/news/vehicle-draft2.htm) (U.S. Architectural and Transportation Barriers Compliance Board [Access Board]). If adopted, the maximum ramp slope permitted when the ramp is deployed to ground (street) level will be reduced from 1:4 to 1:6. Additionally, the proposed revision eliminates varying slope specifications based on the vertical distance between the curb and vehicle floor, taking into account the transportation industry's move towards low floor LATVs. It was not possible to assess actual ramp slopes associated with ingress/egress events in our study. Thus, we cannot know whether or not the observed difficulties related to ramp slope could have been prevented if the Access Board's proposed revisions were in effect.

Uneven exterior ramp thresholds were also thought to be associated with difficulties during ingress. Exterior ramp thresholds were constructed of beveled rubber and met the ADA specification of a slope of 1:2. However, as shown in Figure 9, threshold warping from repeated usage and weathering could result in vertical gaps between the environmental surface terrain and exterior threshold. Additionally, uneven surface terrain and slight ramp surface cross slopes could contribute to vertical gaps at this interface. Some WhMD passengers had apparent difficulties navigating their WhMD over this vertical threshold gap. Such barriers to ingress 
could be addressed through the improved design of exterior thresholds providing a smooth transition between the ramp and environmental surface terrain.

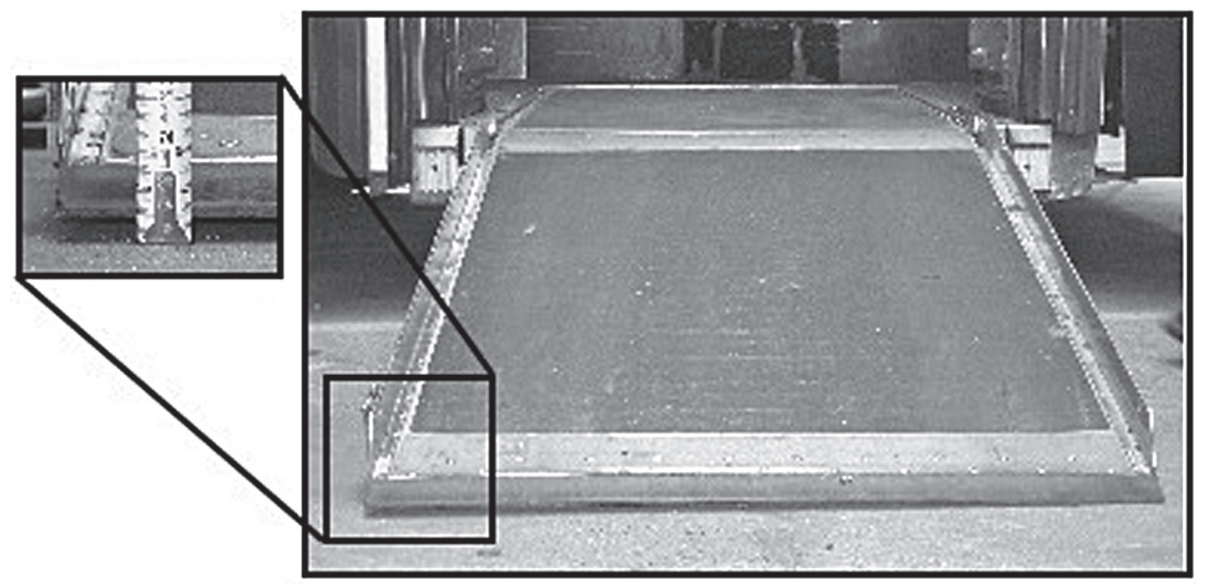

Figure 9. Exterior Ramp Threshold Showing Signs of Wear

Despite the described barriers to ingress/egress, it is important to note that the majority of WhMD passengers successfully boarded and alighted the LATV, reaffirming the relative accessibility of fixed-route, large accessible transit vehicles. However, we posit that in addition to physical barriers, WhMD navigational skills play an important role in successful vehicle ingress/egress. To address this challenge, assistive technology providers, in combination with transit agencies should provide vehicle ingress/egress training to WhMD users intending to travel seated in their WhMD while using public transit. Such efforts may further reduce the number of difficulties and incidents involving WhMD passengers during LATV ingress/egress.

Our findings are representative of one transit agency operating in a medium-sized metropolitan city and are not necessarily generalizable to other transit agencies or geographical regions. Additionally, videos were recorded at a relatively slow frame rate and, in some cases, views may have been blurred or obscured requiring judgment of factors contributing to WhMD user ingress/egress difficulty or incidents. While attempts were made to obtain a randomized distribution of observations during the study period, the distribution of WhMD types and navigational skill of WhMD users may vary across regions and transit agencies. These limitations must be taken into consideration when interpreting and using the findings of our study. 


\section{Conclusions}

Boarding and exiting an LATV was found to present unique challenges to WhMD users and, in some cases, compromised safety. In our study, ingress difficulties/ incidents occurred in 15.6 percent of boardings, while egress difficulties/incidents occurred in 4.9 percent of observations. When observations were normalized by WhMD type, scooters were found to have the greatest incidence (38.9\%) of difficulty during ingress, while power wheelchair users were found to have the highest incidence $(5.9 \%)$ of difficulty during egress. The three most common vehiclerelated factors contributing to WhMD user difficulties during ingress/egress were ramp width, LATV door width and ramp slope.

\section{Acknowledgments}

This study was funded by the National Institute on Disability and Rehabilitation Research (NIDRR) and the Rehabilitation Engineering Research Center (RERC) on Wheelchair Transportation, Grant \#H133E060064. The opinions expressed herein are those of the authors and do not necessarily reflect NIDRR opinions.

\section{References}

Buning, M. E., C. A. Getchell, G. Bertocci, and S. G. Fitzgerald. (2007). Riding a bus while seated in a wheelchair: A pilot study of attitudes and behavior regarding safety practices. Assistive Technology 19: 166-179.

Fitzgerald, S, T. Songer, C. A. Rotko, and P. Karg. (2007). Motor vehicle transportation use and related adverse events among persons who use wheelchairs. Assistive Technology 19: 181-188.

Frost, K. L., and G. Bertocci. (2010). Retrospective review of adverse incidents involving passengers seated in wheeled mobility devices while traveling in large accessible transit vehicles. Medical Engineering \& Physics 32(3): 230-236.

LaPlante, M. (2003). Demographics of wheeled mobility device users. Wheeled Mobility Device Users Workshop Proceedings, Center for Inclusive Design and Environmental Access, State University of New York, Buffalo.

National Highway Traffic Safety Administration. (1997). Wheelchair users injuries and deaths associated with motor vehicle related incidents. Research Note. Department of Transportation. 
National Oceanic Atmospheric Administration (NOAA) and National Weather Service, U.S. Climate Graphs, (c) 2003 - 2007 rssWeather.com. Retrieved September 2009 from http://www.rssweather.com/climate/.

Shaw, G., and T. Gillispie. (2003). Appropriate protection for wheelchair riders on public transit buses. J Rehab Res \& Dev 40(4): 309-19.

U.S. Architectural and Transportation Barriers Compliance Board (Access Board). Draft revisions to the ADA accessibility guidelines for buses and vans, November 19, 2008. Retrieved August 2009, from http://www.access-board.gov/news/ vehicle-draft2.htm.

U.S. Architectural and Transportation Barriers Compliance Board (Access Board). (1990). Americans with Disabilities Act (ADA): Accessibility guidelines for transportation vehicles. 36 CFR Part 1192, Washington, D.C.

\section{About the Authors}

Karen L. Frost, Ph.D., MBA (k.frost@louisville.edu) is an Assistant Professor in the Department of Mechanical Engineering at the University of Louisville, where she conducts research in the area of wheelchair transportation safety. She also is a staff member of the NIDRR-funded Rehabilitation Engineering Research Center on Wheelchair Transportation and Safety.

Gina E Bertocci, Ph.D., P.E. is at the University of Louisville where she is the Endowed Chair of Biomechanics and Professor in the Departments of Mechanical Engineering, Bioengineering and Pediatrics. She is also the Associate Director of the RERC on Wheelchair Transportation Safety and the Director of the Injury Risk Assessment and Prevention Laboratory, a multi-disciplinary laboratory conducting research focused on injury risk assessment.

SHERYLL SISON, M.Eng, is a mechanical engineer and recent graduate of the University of Louisville. 